\title{
Inoculação e adubação nitrogenada sobre a nodulação e a produtividade de grãos de feijão-caupi
}

\author{
Inoculation and nitrogen fertilization on nodulation and grain yield of cowpea
}

\author{
Terezinha Ferreira Xavier ${ }^{\mathrm{I}}$ Ademir Sérgio Ferreira de Araújo ${ }^{\mathrm{II}^{*}}$ \\ Valdinar Bezerra dos Santos ${ }^{\mathrm{II}}$ Francilene Leonel Campos ${ }^{\mathrm{III}}$
}

\begin{abstract}
O objetivo deste trabalho foi avaliar a influência da inoculação e da adubação nitrogenada sobre a nodulação e a produtividade do feijão-caupi. O estudo foi conduzido em uma área experimental, em Parnaíba, PI. Os tratamentos foram dispostos em delineamento em blocos ao acaso em arranjo fatorial de $5 \times 2$, sendo cinco doses de $N(0,20,40,80$ e $160 \mathrm{~kg}$ $\mathrm{ha}^{-1}$ de N) e dois tratamentos microbiológicos (com e sem inoculação). No tratamento com inoculação, foi utilizado um inoculante contendo Bradyrhizobium sp, estirpe BR2001. A avaliação da nodulação e da produtividade de grãos foi realizada aos 36 e 65 dias após a emergência das plantas, respectivamente. Houve interação significativa entre inoculação e doses de $N$ para todas as variáveis analisadas, sendo a regressão quadrática a que melhor ajustou-se aos dados observados. O número e a massa dos nódulos apresentaram, no tratamento com inoculação, valores máximos de 29 nódulos e 118,6mg nas doses estimadas de 34,5 e $17,5 \mathrm{~kg} \mathrm{ha}^{-1}$ de $\mathrm{N}$, respectivamente. Os resultados obtidos no presente estudo indicam que a produtividade de grãos do feijão-caupi aumenta com o uso da inoculação e o efeito dessa prática é favorecido quando o feijão-caupi é adubado com no máximo $20 \mathrm{~kg} \mathrm{ha}^{-1}$ de $\mathrm{N}$.
\end{abstract}

Palavras-chave: nitrogênio, fixação biológica de $\mathrm{N}$, Bradyrhizobium, Vigna unguiculata.

\section{ABSTRACT}

The aim of this research was to evaluate the influence of inoculation and nitrogen fertilization on nodulation and grain yield of cowpea. The experiment was carried out in an experimental area in Parnaíba, PI. The treatments were disposed in a completely randomized block in factorial design of $5 \times 2$, consisted of five $N$ levels $\left(0,20,40,80\right.$ and $160 \mathrm{~kg} \mathrm{ha}^{-1}$ $N)$ and two microbiological treatments (with and without inoculation). In the treatment with inoculation, an inoculant was used containing Bradyrhizobium sp, strain BR2001. The evaluation of nodulation and grain yield was performed 36 and 65 days after plant emergency, respectively. There was significative interaction among inoculation and $N$ levels in all variables, being the quadratic regression the one that best adjusted to data. The number and mass of nodules presented, in the treatment with inoculation, maximum values calculated of 29 nodules and $118,6 \mathrm{mg}$ in doses estimated of 34.5 and $17.5 \mathrm{~kg} \mathrm{ha}^{-1} \mathrm{~N}$, respectively. The results indicate that the grain yield increase by use of inoculation and the effect of this practice is favored when the cowpea is fertilized with maximum $20 \mathrm{~kg} \mathrm{ha}^{-1}$ of $N$.

Key words: nitrogen, biological N fixation, Bradyrhizobium, Vigna unguiculata

O feijão-caupi (Vigna unguiculata (L.) Walp), também conhecido por feijão macassar ou feijãode-corda é uma das alternativas de alimento para a população de baixa renda da região Nordeste do Brasil. Pelo seu alto valor nutritivo, o feijão-caupi é cultivado principalmente para a produção de grãos, secos ou verdes, para consumo humano. A cultura é uma das mais cultivadas no Estado do Piauí, ocupando uma área de aproximadamente 210 mil hectares (IBGE, 2006). Entretanto, baixos níveis de produtividade têm sido observados nas áreas produtoras do Estado e uma das principais causas é a baixa disponibilidade de nutrientes

IUniversidade Estadual do Piauí (UESPI), Campus de Parnaíba, Parnaíba, PI, Brasil.

IIUniversidade Federal do Piauí (UFPI), Centro de Ciências Agrárias, 64049-550, Teresina, PI, Brasil. E-mail: asfaruaj@yahoo.com.br.

*Autor para correspondência.

IIUFPI, Campus Helvídio Nunes, 64202-220, Parnaíba, PI, Brasil. 
no solo, principalmente nitrogênio (N) (XAVIER et al., 2007).

O N é um dos nutrientes exigidos em maior quantidade pela cultura do feijoeiro. Segundo MALAVOLTA \& LIMA FILHO (1997), para atingir a produtividade de $1,5 \mathrm{Mg} \mathrm{ha}^{-1}$ de grãos, são necessários $100 \mathrm{~kg} \mathrm{ha}^{-1}$ de N. A adubação mineral é a principal forma de fornecimento de $\mathrm{N}$ às plantas. No entanto, a aplicação de $\mathrm{N}$ mineral em solos tropicais normalmente apresenta baixa eficiência de recuperação pelas plantas, sendo, segundo DUQUE et al. (1985), normalmente inferior a 50\%, podendo, em determinadas situações, em solos arenosos, não superar entre 5\% e 10\%, devido às grandes perdas por lixiviação e volatilização (OSINAME et al., 1983).

Uma característica importante que as leguminosas, tais como o feijão-caupi, possuem é a capacidade de, em simbiose com bactérias do gênero Rhizobium, realizar a fixação biológica do $\mathrm{N}_{2}$ (FBN) que, segundo FRANCO et al. (2002), é uma das formas de aumentar a produtividade de leguminosas e substituir os adubos nitrogenados minerais. A FBN é reconhecidamente eficiente em feijão-caupi que, quando bem nodulado, pode atingir altos níveis de produtividade (RUMJANEK et al., 2005). Por um lado, o suprimento de $\mathrm{N}$ via fertilização mineral influencia o processo de FBN em leguminosas, uma vez que as plantas podem absorver diretamente o $\mathrm{N}$ presente no solo (OLIVEIRA et al., 2004). Por outro lado, o processo pode ocorrer com eficiência em condições de baixa disponibilidade de $\mathrm{N}$ no solo (FRANCO \& NEVES, 1992), embora seja recomendado o uso de pequenas doses de N aplicadas no plantio (HUNGRIA et al., 1994) para melhorar o crescimento das plantas e promover efeito sinergístico sobre a nodulação (TSAI et al., 1993). O objetivo deste trabalho foi avaliar a influência da inoculação e da adubação nitrogenada sobre a nodulação e a produtividade em feijão-caupi.

O trabalho foi realizado durante os meses de março a maio de 2006 em uma área experimental no Distrito de Irrigação dos Tabuleiros Litorâneos do Piauí,

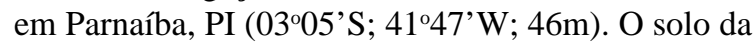
área experimental é classificado como Neossolo Quartazarênico órtico típico. O clima é do tipo Aw’, tropical chuvoso, de acordo com a classificação de Koppen, com precipitação média anual de aproximadamente 1000mm e umidade relativa do ar em torno de $75 \%$. A área experimental, nos últimos três anos, vinha sendo utilizada para o cultivo de melancia e de milho, em sistema irrigado, e nunca havia sido utilizada para plantio de feijão-caupi.

As características químicas do solo antes da instalação do experimento foram pH 6,4; Matéria orgânica 8,5g kg-1; P, 35mg dm-3; K, 0,15; Ca, 1,1; Mg, 0,5 e CTC $1,85 \mathrm{cmol}_{c} \mathrm{dm}^{-3}$ (EMBRAPA, 1999), determinadas no Laboratório de Solo e Água da Embrapa Meio Norte. O solo foi preparado por meio de aração e gradagem leve e recebeu adubação mineral com $\mathrm{P}$ e K, utilizando-se $80 \mathrm{~kg} \mathrm{ha}^{-1}$ de $\mathrm{P}_{2} \mathrm{O}_{5}$, na forma de superfosfato simples, e $60 \mathrm{~kg} \mathrm{ha}^{-1} \mathrm{de}_{2} \mathrm{O}$, na forma de cloreto de potássio. Os tratamentos foram dispostos em um delineamento de blocos ao acaso em arranjo fatorial $5 \mathrm{x} 2$, sendo cinco doses de $\mathrm{N}$, na forma de uréia, $\left(0,20,40,80\right.$ e $160 \mathrm{~kg} \mathrm{ha}^{-1}$ de $\left.\mathrm{N}\right)$ e dois tratamentos microbiológicos (com e sem inoculação), com quatro repetições. As doses 20 e $40 \mathrm{~kg} \mathrm{ha}^{-1}$ de $\mathrm{N}$ foram aplicadas no plantio e as doses 80 e $160 \mathrm{~kg} \mathrm{ha}^{-1}$ de $\mathrm{N}$ foram parceladas em duas vezes (metade no plantio e o restante em cobertura aos 30 dias após a emergência). Na semeadura foram utilizadas sementes de feijão-caupi (Vigna unguiculata L. Walp.), cultivar "BRS-Guariba”. No tratamento com inoculação, foi utilizado um inoculante à base de turfa contendo Bradyrhizobium sp, estirpe BR2001. A inoculação foi feita utilizando-se uma solução açucarada a 1\% para servir como aderente para o inoculante, que foi aplicado na dose de $500 \mathrm{~g}$ de inoculante para $50 \mathrm{~kg}$ de sementes.

A parcela experimental teve dimensões de $3,2 \mathrm{~m} \times 5,0 \mathrm{~m}$ e constou de quatro linhas de 5,0m de comprimento, tendo como área útil as duas linhas centrais. O espaçamento entre linhas foi de $0,8 \mathrm{~m}$. Dentro da linha, o espaçamento foi de $0,2 \mathrm{~m}$ entre covas (cinco covas por metro linear), o que resultou em 25 covas por linha, onde foram colocadas três sementes por cova. O desbaste foi feito aos 10 dias após a semeadura, deixando-se uma planta por cova. As parcelas experimentais foram irrigadas diariamente e o controle de plantas invasoras foi realizado por meio de capina manual com auxílio de enxadas.

A coleta dos dados de nodulação foi realizada aos 36 dias após a emergência (correspondente ao estádio de florescimento). Para a determinação da nodulação foram escolhidas, ao acaso, quatro plantas na área útil de cada parcela. As plantas foram retiradas cuidadosamente do solo, cortadas na base do caule, separando-se a parte aérea das raízes. Os nódulos foram destacados, contados e colocados para secar em estufa a $65^{\circ} \mathrm{C}$ por 72 horas, sendo, em seguida, determinada sua massa. Na maturação de colheita, aos 65 dias após a emergência, foi avaliada a produção de grãos mediante a colheita em $4 \mathrm{~m}^{2}$ da área útil de cada parcela, com o resultado em $\mathrm{Mg} \mathrm{ha}^{-1}$ de grãos a $13 \%$ de umidade. Os resultados obtidos foram submetidos à análise de variância e à análise de regressão polinomial empregando-se o programa de análise estatística SAS.

Ciência Rural, v.38, n.7, out, 2008. 
Houve efeito significativo $(\mathrm{P}<0,05)$ entre inoculação e doses de $\mathrm{N}$ para todas as variáveis analisadas, sendo a regressão quadrática a que melhor ajustou-se aos dados observados. O número e a massa dos nódulos apresentaram, no tratamento com inoculação, valores máximos calculados, por meio das equações de regressão, de 29 nódulos e 118,6mg nas doses estimadas de 34,5 e $17,5 \mathrm{~kg} \mathrm{ha}^{-1}$ de N (Figura 1a e 1b), mostrando que, em feijão-caupi, a adição de pequenas quantidades de $\mathrm{N}$ no solo pode favorecer a nodulação. Estes resultados concordam com os obtidos por SILVA et al. (1993), para feijoeiro comum e MENDES et al. (2003), para soja. Por outro lado, houve diminuição da nodulação quando foram adicionadas doses superiores a $80 \mathrm{~kg} \mathrm{ha}^{-1}$ de $\mathrm{N}$, o que mostra que a simbiose é inibida pela presença de doses elevadas de $\mathrm{N}$ no solo. Tais resultados concordam com os obtidos por SUMMERFIELD et al. (1985), que observaram que quanto mais $\mathrm{N}$ mineral disponível no substrato de crescimento da leguminosa menor será a nodulação.

No presente estudo foi observada a presença de nódulos no tratamento sem inoculação,

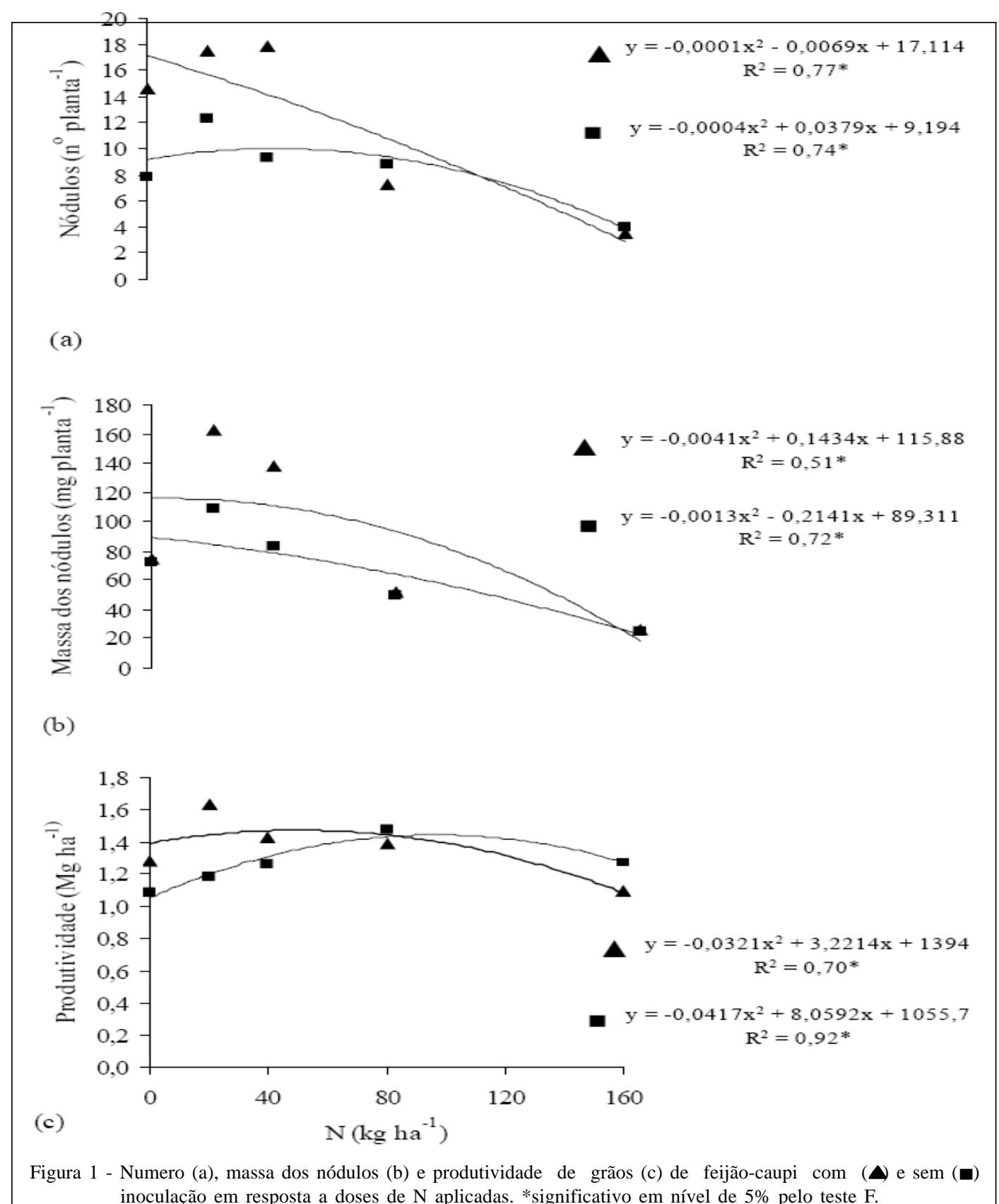

Ciência Rural, v.38, n.7, out, 2008. 
indicando a presença de bactérias nativas capazes de nodular o feijão-caupi no solo, uma vez que não houve inoculações em cultivos anteriores na área experimental. Entretanto, as bactérias introduzidas pela inoculação apresentam maior eficiência e competitividade, uma vez que são selecionadas para tais características (HUNGRIA et al., 1994).

Considerando valores medidos, observa-se que, na ausência de adubação nitrogenada, com aproximadamente metade dos nódulos (15 e 8 nódulos para os tratamentos com e sem inoculação, respectivamente), o tratamento sem inoculação apresentou massa de nódulos semelhantes ao tratamento com inoculação (aproximadamente 75mg). Por outro lado, para o tratamento com inoculação e na dose de $20 \mathrm{~kg} \mathrm{ha}^{-1}$ de $\mathrm{N}$, observa-se que com um incremento de aproximadamente três nódulos ocorreu um aumento significativo na massa dos nódulos de aproximadamente $85 \mathrm{mg}$ em relação à testemunha sem $\mathrm{N}$. Estes resultados indicam que a aplicação de pequena dose de $\mathrm{N}$ para o feijão-caupi proporcionou incremento na massa dos nódulos já formados e confirma a hipótese relatada anteriormente. Segundo TSAI et al. (1993), embora o crescimento dos nódulos seja sensível ao excesso de $\mathrm{N}$, pequenas doses podem estimular tanto o crescimento da planta como aumentar a massa de nódulos produzidos. Esta observação é importante, pois, segundo DOBEREINER (1966), há uma correlação positiva entre a massa nodular e a quantidade de $\mathrm{N}$ acumulado em leguminosas. Tal correlação positiva foi encontrada por WADISIRISUK \& WEAVER (1985) em feijão-caupi.

Os resultados de produtividade de grãos obtidos com e sem inoculação indicam um efeito positivo da inoculação e da aplicação de pequena quantidade de $\mathrm{N}$ ( $20 \mathrm{~kg} \mathrm{ha}^{-1}$ ). O modelo ajustado mostra, com a inoculação, um efeito de aproximadamente $338 \mathrm{e}$ $220 \mathrm{~kg} \mathrm{ha}^{-1}$ de grãos para as doses de 0 e $20 \mathrm{~kg} \mathrm{ha}^{-1}$ de N, respectivamente. Considerando-se os valores medidos, as diferenças, para essas doses, entre os tratamentos com e sem inoculação, são de 283 e $454 \mathrm{~kg} \mathrm{ha}^{-1}$ de grãos. Entretanto, com a inoculação, a produtividade máxima calculada foi de $1.474 \mathrm{~kg} \mathrm{ha}^{-1}$ para uma dose estimada de 50,17kg ha-1 de N. Esta produtividade supera à obtida nas doses $0 \mathrm{~kg} \mathrm{ha}^{-1}$ de $\mathrm{N}$ em apenas $76 \mathrm{~kg} \mathrm{ha}^{-1}$ de grãos. Devido ao custo da adubação nitrogenada, a utilização da dose estimada de $50 \mathrm{~kg} \mathrm{ha}^{-1}$ de $\mathrm{N}$ não seria recomendada quando se utiliza a inoculação. Por outro lado, a dose de $20 \mathrm{~kg} \mathrm{ha}^{-1}$ de $\mathrm{N}$, associada à inoculação, proporcionou uma maior produtividade medida e superior a máxima calculada em aproximadamente $150 \mathrm{~kg}$ $\mathrm{ha}^{-1}$, sugerindo que esta dose pode ser considerada ideal ou máxima a ser aplicada no solo em associação com a inoculação das sementes.

A produtividade de grãos do feijão-caupi aumenta com o uso da inoculação e o efeito dessa prática é favorecida quando o feijão-caupi é adubado com no máximo $20 \mathrm{~kg} \mathrm{ha}^{-1}$ de $\mathrm{N}$.

\section{REFERÊNCIAS}

EMBRAPA... Manual de análises químicas de solos, plantas e fertilizantes. Brasília, 1999. 370p.

DOBEREINER, J. Evaluation of nitrogen fixation in legumes by the regression of total plant nitrogen with nodule weight. Nature, v.210, p.850-852, 1966.

DUQUE, F.F. et al. The response of field grown Phaseolus vulgaris to Rhizobium inoculation and quantification of $\mathrm{N}_{2}$ fixation using ${ }^{15} \mathrm{~N}$. Plant and Soil, v.88, p.333-343, 1985.

FRANCO, A.A.; NEVES, M.C.P. Fatores limitantes à fixação biológica de nitrogênio. In: CARDOSO, E.J.B.N. et al. (Eds). Microbiologia do solo. Campinas: SBCS, 1992. p.257-282.

FRANCO, M.C. et al. Nodulação em cultivares de feijão dos conjuntos gênicos andino e mesoamericano. Pesquisa Agropecuária Brasileira, v.37, p.1145-1150, 2002.

HUNGRIA, M. et al. Fixação biológica do nitrogênio em soja. In: ARAUJO, R.S.; HUNGRIA, M. (Eds). Microrganismos de importância agrícola. Brasília: Embrapa,1994. p.9-90.

IBGE... Levantamento sistemático da produção agrícola. Relatório geral: culturas temporárias da região nordeste. Acesso em 18 de agosto de 2006. On line. Disponível em http:// www.ibge.gov.br/home/estatistica/indicadores/agropecuaria/lspa/ defalt.shtm.

MALAVOLTA, E.; LIMA FILHO, O.F. Nutrição e adubação do feijoeiro. In: FANCELLI, A. L.; DOURADO NETO, D. (Eds.). Tecnologia da produção de feijão irrigado. Piracicaba: ESALQ, 1997. p.22-51

MENDES, I.C. et al. Resposta da soja à adubação nitrogenada na semeadura e inoculação com Bradyrhizobium em sistema de plantio direto e convencional em um Latossolo da região dos cerrados. Revista Brasileira de Ciência do Solo, v.27, p.81-87, 2003.

OLIVEIRA, W.S. et al. Alfalfa yield and quality as function of nitrogen fertilization and symbiosis with Sinorhizobium meliloti. Scientia Agricola, v.61, p.433-438, 2004.

OSINAME, O. et al. Effect nitrifications inhibitions of the fate and efficiency of nitrogenoms fertilizers under simulated humid tropical condutions. Tropical Agriculture, v.60, p.211217, 1983.

Ciência Rural, v.38, n.7, out, 2008. 
RUMJANEK, N.G. et al. Fixação biológica do nitrogênio. In: FREIRE FILHO, F.R. et al. (Eds). Feijão-Caupi: avanços tecnológicos. Brasília: Embrapa, 2005. p.281-335.

SILVA, P.M.D. et al. Response to inoculation and N fertilization for increased yield and biological nitrogen fixation of common bean (Phaseolus vulgaris). Plant and Soil, v.152, p.123-130, 1993.

SUMMERFIELD, R.J. et al. The physiology cowpea. In: SINGH, S.R.; RACHIE, K.O. (Eds). Cowpea research, production and utilization. Chichester: John Wiley, 1985. p.66-101.
TSAI, S.M. et al. Minimizing the effect of mineral nitrogen on biological nitrogen fixation in common bean by increasing nutrient levels. Plant and Soil, v.152, p.131-138, 1993.

WADISIRISUK, P.; WEAVER, R.W. Importance of bacteroid number in nodules and effective nodule mass to dinitrogen fixation by cowpeas. Plant and Soil, v.87, p.223-231, 1985.

XAVIER, T.F. et al. Ontogenia da nodulação em duas cultivares de feijão-caupi. Ciência Rural, v.37, p.572-575, 2007. 